Document downloaded from:

http://hdl.handle.net/10251/51297

This paper must be cited as:

Payri Marín, R.; Novella Rosa, R.; García Martínez, A.; Domenech Llopis, V. (2014). A New Methodology to Evaluate Engine Ignition Systems in High Density Conditions. Experimental Techniques. 38(3):17-28. doi:10.1111/j.1747-1567.2012.00818.x.

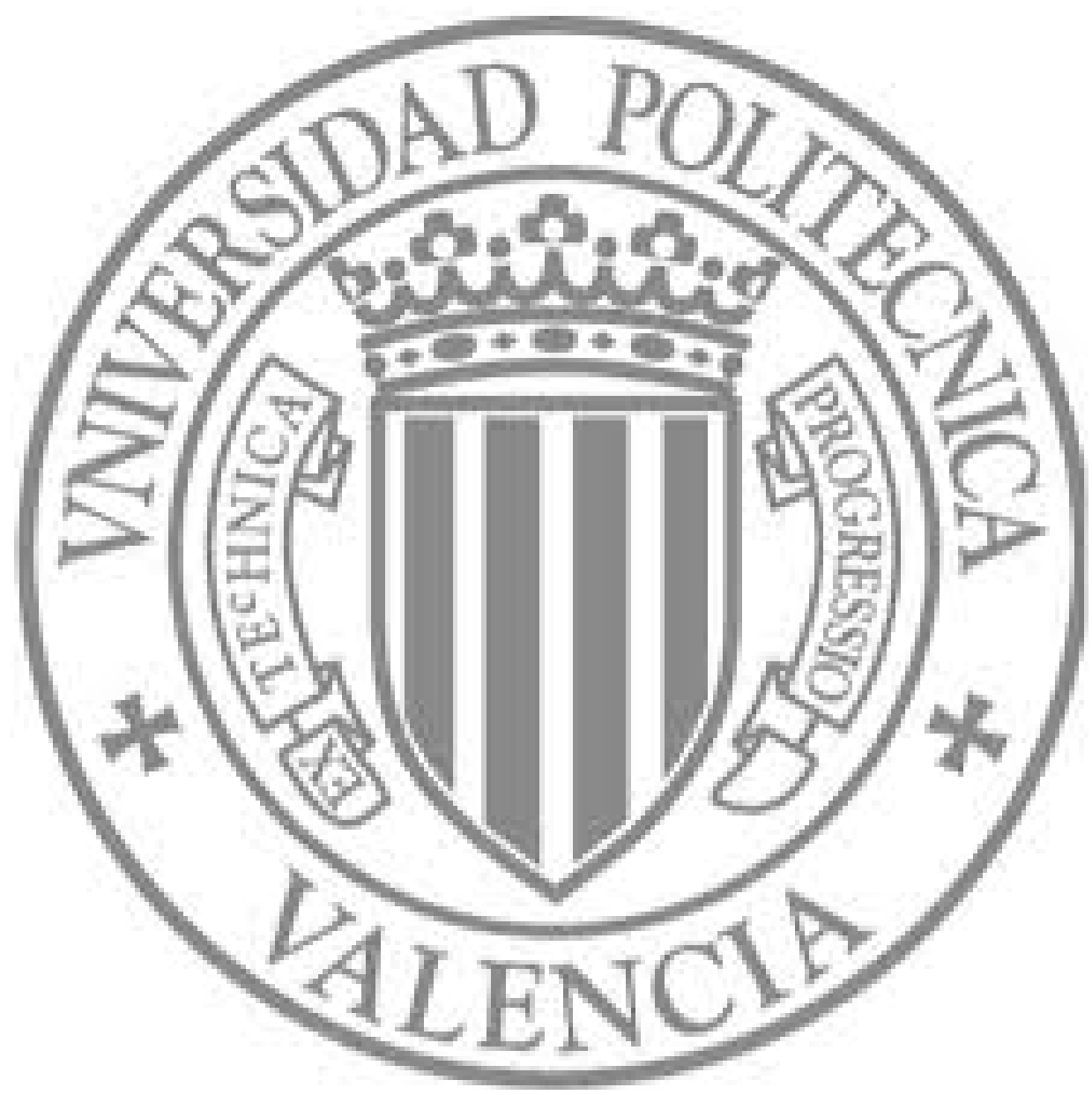

The final publication is available at

http://dx.doi.org/10.1111/j.1747-1567.2012.00818.x

Copyright Society for Experimental Mechanics (SEM) 


\title{
A new methodology to evaluate engine ignition systems in high density conditions
}

\author{
R. Payri*, R. Novella, A. Garcia and V. Domenech \\ CMT-Motores Térmicos \\ Universitat Politécnica de Valencia \\ Camino de Vera s/n, 46022, Valencia (Spain) \\ Tel. (+34) 963877650 / Fax (+34) 963877659
}

\begin{abstract}
In this research a new methodology to evaluate the operation of spark ignition systems in high density conditions is presented. New requirements in engines and new combustion modes demand more from these systems. One of the most important new requirements is the increase in density. Thus, a better understanding of the effects of high density and the behavior of the ignition system in these conditions seems necessary. To carry out this work two experimental facilities have been used: a transparent constant volume vessel, and an optical engine to simulate real engine conditions. In both cases a double study has been performed, one of the electrical signals and derivate parameters and other using images obtained with a high speed camera. The methodology has been applied for different cases of pressure, intake temperature and other parameters that affect the density. Results show that an increase in density causes a decrease in integrated power. Additionally, the dispersion in this integrated power increases too. Finally, the combination of images and signals allows ensuring the operation of the system near its limits and therefore seems an appropriate methodology to study the ignition systems. Moreover it is validated that the results of the ambient transparent constant volume vessel follow the same trends and values as the realistic ones.
\end{abstract}

Keywords: Ignition system, spark plug, electric signals, high density test rig, optical engine 


\section{Introduction and problem description}

In the last decades, the scientific and technical communities of Internal Combustion Engines (ICE) are facing two of the most important challenges, the reduction of pollutant emissions and the increase in overall engine efficiency [1-2]. Accordingly, great efforts have been made in gasoline engines [3]. Specifically, in this framework the ignition process has revealed itself as a fundamental aspect to achieve a stable and efficient combustion with low emissions in a gasoline direct injection engine [4].

New combustion modes in current and future gasoline engines are based on stratification of the engine charge, introducing the fuel directly in the combustion chamber in a lean ambient (SIDI - Spark Ignition Direct Injection) [5].

In this context, several important changes have been introduced in the engine hardware compared to conventional gasoline engines because mixture formation calibration for the entire range is an essential basic prerequisite for achieving reliable, good combustion with high efficiency and minimal emissions [6]. The injection pressure has been increased (around 2000 bar), the piston shape changes from that of the homogeneous gasoline engines to one that guides the fuel from the injection nozzle to the spark plug, and the exhaust gas recirculation levels used have been strongly increased. Additionally, to increase the reduction in consumption achieved with mixture stratification in a lean ambient, the downsizing concept in gasoline engines has been applied [7]. In this sense, higher supercharging conditions have been considered to provide proper engine performances. It is particularly important for combustion in gasoline engines with direct injection that an ignitable mixture is present in the vicinity of the spark plug at ignition point, irrespective of engine load and speed. This imposes special requirements on a range of parameters, in particular the intake flow, the shape of the combustion chamber, the compression ratio, the position of the injection nozzle and the spark plug system.

In these new gasoline combustion modes where the range of the flammability limits has been reduced and, consequently, the capability to establish a flame has been decreased, the influence of the ignition system is even more important than in conventional ones. A relatively rich mixture is present in the vicinity of the spark plug and a very lean mixture can be found in the wall area of the combustion chamber, hence the precision in the ignition of the spark plug and the energy it releases become more important [8]. The requirements with respect to the ignition system characteristics are very high for combustion processes with heterogeneous mixture. Chemically inactive mixtures, as available in high

Published as: Experimental Techniques, Vol 38 (3), pages 17-28, May/June 2014 
exhaust-gas recirculation rates and lean air/fuel ratios, show fluctuations in retarded ignition timings or even misfire when using a conventional ignition system. Therefore a proper ignition system must ensure the capability to initiate the flame propagation.

Considering a conventional coil ignition system (inductive ignition system) where the primary function of the ignition coil is to save the energy required for generating the high voltage, the physical processes that occur between the electrodes of a spark plug normally imply three sequential phases, the breakdown, the arc and glow phase, and finally the shutdown. In the first step, the dielectric breakdown takes place. This first phase is characterized by a high voltage, around $20-40 \mathrm{kV}$, breaking the air dielectric and causing the formation of a conductive channel of ionized gas. The required ignition voltage depends strongly on the density of air in the combustion chamber and thus also on the timing of the ignition, electrode geometry, electrode material, and electrode gap [9]. In the second step, the current flows between the electrodes and the electric arc appears, along with a reduction of the voltage $(5-10 \mathrm{KV})$, this is the longest step. After few microseconds, the electric arc is extinguished and hence the potential difference between the electrodes of the spark plug becomes low once again [10].

As it is explained in the literature and introduced in the previous paragraphs, the evaluation of the ignition process in a stratified and supercharged engine with high levels of EGR is quite complex. Thus, as a first approach, non reactive conditions without fuel injection will be used with the aim of isolating the effects of increasing the density in the ignition system. Subsequently, a more realistic study with an optical engine is performed. In these tests different thermodynamic conditions varying pressure and temperature are evaluated. Therefore, the main objective of this research is to develop a methodology for the systematic evaluation of the spark ignition systems used in automotive gasoline engines under controlled high density conditions representative of new combustion modes.

\section{Experimental facilities}

Two different facilities are used in this study. The first one consists of a homemade ambient temperature test rig manufactured mainly in aluminum featuring an optical quartz access which allows us to study the spark plug discharge characteristics of the ignition system with constant and controlled ambient conditions; specifically no air movement is considered. The second facility is fully equipped with an 
optical single-cylinder engine test rig which provides optical access and is capable of reproducing the real thermodynamic conditions inside the chamber.

\section{Ambient temperature test rig}

Figure 1 represents a complete assembly of the different parts of the ambient temperature test rig. The general setup consisted of an ignition coil Lucas electronic DLB 198 triggered by a homemade electronic ignition module. The ignition was triggered by a TTL METRIX GX239 pulse from a function generator. All the electric signals were electrically isolated. A $10 \mathrm{kOhm}$ high-tension ignition wire Lucas silicone 15 was used for all of the measurements; a solid copper conductor was used for some measurements investigating the effects associated with spark plug and ignition resistance. Different tests were made to maximize the efficiency of the system by considering L-C factors, for not to be affected greatly from the other electrical signals through electronic screening. A NKG-8-RH spark plug was examined and used in the study. The internal resistances of the spark plug were measured before and after the tests were conducted. It is interesting to note that several of the new plugs and coils had higher resistance values before the tests were performed than after finishing them. Voltage traces were measured using a Tektronix model P6015A high voltage probe (rise time $\sim 5 \mathrm{~ns}$ ). Current traces were measured using a HEME current probe PR1030 and with current transducers with a sensitivity of 0.01volt/amp and rise time of 20 ns. An oscilloscope was used to capture the test signals, in this case a YOKOGAWA DL716 system with $200 \mathrm{MHz}$ frequency acquisition; the signals were subsequently transferred to a PC. Two different voltage measurements were made, one at the top of the spark plug, outside the test rig, and another one at the spark gap inside. The high voltage probe (Tektronix) was used to measure the secondary voltage and two clamp meters were used for the measurement of the current signals. One measured how the system was charged before the electric arc discharge was produced (primary current), while the other measured the discharge of the secondary. Finally the power signal of the spark plug was fired by a pulse generated by the controlled TTL function generator to simulate different rates of spark discharge and different engine conditions. The conditions for the measurements were: a high tension wire with $15 \mathrm{kOhm}$ resistance, a spark plug with an internal resistance of $20 \mathrm{kOhm}$ and a gap of $0.7 \mathrm{~mm}$. It is worthy to note that the different electrical equipment used in the ambient temperature test rig will also be used in the optical single-cylinder engine in order to record all the necessary signals. 
As it was discussed, specific equipment was designed to perform the tests in controlled and ambient atmosphere. The most relevant design criterion was to provide enough capability for visualization of the spark plug discharge by means of a proper sized optical access. The dead volume of the chamber was designed so that it was equal to the volume of the optical engine and had the capability to implement the different inlet and outlet systems required. Thus, one hole was drilled to allow the spark plug introduction and another two to place the pressure sensor and the duct for the nitrogen inlet. Additionally, other criteria were considered, such us the mechanical resistance of the entire assembly. So, considering that the maximum pressure in test is set below 60 bar and that the temperature is kept constant within the range of 298-350 K, along with previous experience in designing chambers with similar requirements [11] [12], results in the fact that the test rig was manufactured using aluminum 6045. For the optical access a quartz window was selected. This quartz window is a cylinder of $60 \mathrm{~mm}$ diameter and $50 \mathrm{~mm}$ thickness.. Figure 2 shows a scheme with different views.

Finally, to carry out the acquisition of the discharge images the spark plug is positioned perpendicular to the high speed camera, therefore allowing the study of the phenomena taking place at the electrodes. So, in this case, once the test rig is set it is necessary to adjust the camera. In this study, a Phantom V12 high speed camera was used. The recording speed was 20000 frames per second with a resolution of 256x256 pixels and a exposure time of 50 microseconds. Furthermore, an optical lens 24-70 mm MACRO F/2.8 was used along with continuous light source for a correct illumination of the entire chamber. The distance between the quartz window of the test rig and the camera objective is $150 \mathrm{~mm}$. This set up aims to allow very close observation of the fundamental discharge process in stable conditions that takes place between the electrodes in the nitrogen test rig.

\section{Optical single-cylinder engine facility}

To analyze the dynamic response of the ignition system under real conditions the experimental tests were performed in an optical single-cylinder DI Diesel engine with 4 valves, 0.5451 displacement and a modified cylinder head. Specifically, one of the exhaust valves was removed to allow the spark plug

insertion. Thus, the engine is installed in a fully instrumented test cell, with all the auxiliary facilities required for operation and control. Figure 3 shows a scheme of the installation.

Published as: Experimental Techniques, Vol 38 (3), pages 17-28, May/June 2014 
In figure 3 the complete test cell is represented. The engine was modified to reproduce high density conditions similar that those of new SIDI engines. The compression ratio was adjusted at 14.7:1 and intake temperature and air were controlled. Oil and water temperatures were also controlled at the same temperature via PID. Intake air is supplied by means of a screw compressor, and flows through a dryer, a filter, two mass flow meters, a liquid gas heat exchanger, a plenum chamber and a second heat exchanger before entering the engine. The intake air temperature was measured at different points, but the control measurement for the PID was taken with a thermocouple placed a few millimeters upstream of one of the intake valves. Intake flow measurements were performed simultaneously with two flow meters. A hot wire flow meter (Siemens 5WK9 621 PBT-GF-30), which was selected to allow proper measurement of the low mass flow of the single-cylinder engine operating at low speed, was used as the main device. The facility has a heater before the settling chamber to condition the inlet temperature. The main intake pressure at the inlet plenum chamber can be set between 1.2 and 3.2 bar. A second volumetric mass flow meter was located downstream of the former for a twofold reason: on the one hand, it allowed on-line control of the proper behavior of the hot wire meter and, on the other hand, it allowed a further reduction of pressure fluctuations thus increasing the measurement accuracy of the main flow meter. Then, gas pressure was adjusted within the intake settling chamber while intake temperature was controlled at the intake manifold. The exhaust backpressure created by the turbine in the real engine was replicated by means of a valve placed in the exhaust system, controlling the pressure at the exhaust settling chamber. The oxygen concentration variation was performed using a synthetic EGR system. The decrease in oxygen concentration was generated by mixing nitrogen with fresh air. A system for measuring mass flow rate of nitrogen (Siemens 5WK9 628 PBT-GF-30) was installed in the facility. This nitrogen reaches the settling chamber where it mixes with the fresh air. After mixing in this large volume, oxygen concentration was monitored at the intake manifold by means of a lambda sensor. The mixture was controlled by increasing or decreasing the mass flow rate of nitrogen, thus various concentrations of XO2could be achieved.

In addition in the optical version the engine is equipped with an elongated piston with a cylindrical bowl, its dimensions being $45 \times 18 \mathrm{~mm}$ (diameter $\mathrm{x}$ depth), which allows optical access to the combustion chamber through a sapphire window placed in its bottom. Below the piston bowl, an elliptical mirror is placed on the cylinder axis. In front of the mirror a high speed camera is positioned to record radiation that comes from the combustion chamber. All this setup is mounted on an extender that sits between the 
cylinder head and the engine. Figure 4 shows how the acquisition of the discharge images in this facility was performed. As discussed, the whole optical system installed in this optical engine facility has a piston with an adaptation of a sapphire window, an elliptical mirror that allows to reflect the light that comes from the combustion or otherwise illuminate the inside of the cylinder, an external light source equipment with optical fiber and a collimator, and finally a high speed camera to obtain images of the entire process. The images are taken with a high speed CMOS camera Phantom V12, equipped with a $100 \mathrm{~mm}$ focal length ZEISS and an image resolution of 512 x 512 pixels. For this resolution the images have been recorded at an acquisition frequency of $20000 \mathrm{fps}$ and 100 microseconds exposure time were used for capturing the spark plug discharge process events. In most cases of this study the images have been recorded without external illumination and the camera settings have been adjusted to avoid the sensor saturation, in such a way that only the light provided by the discharge of the spark plug and combustion process was captured.

\section{Methodology}

This section describes the methodology that has been developed in order to understand the ignition system response and the spark plug discharge phenomena. This methodology combines classical electrical analysis with post-processing of the different signals and optical techniques. Figure 5 shows a sketch of the general methodology used for the ignition system analysis in high density conditions.

\section{Ambient temperature test rig operation and methodology}

In a first stage of the study, the ambient temperature test rig is used to study the effect of density on the ignition system in static conditions; this requires working without changing the temperature, without air movement, and without oxygen in the chamber. To perform the study a wide sweep of densities has been carried out including the range of new gasoline engines. In automotive gasoline engines representative temperatures and pressures at the start of spark discharge are $550 \mathrm{~K}$ and 10-15 bar [10] and in new combustion modes is near 20-25 bars.

Thus, in this stage of the study the chamber is filled with nitrogen to maintain an inert atmosphere, therefore allowing performing the test under stable conditions. Consequently, a bottle of N2 is needed to pressurize the system. Considering that the temperature of the N2 is kept constant during all tests (298K),

Published as: Experimental Techniques, Vol 38 (3), pages 17-28, May/June 2014 
the system density will be limited to $40 \mathrm{~kg} / \mathrm{m} 3$ for the study proposed and therefore the maximum pressure will be around 60 bar. The nitrogen filling is controlled with a pressure reducer and a pressure gauge before its introduction in the chamber. In a first step it is filled up to the reference pressure of the test rig. Then, when the pressure system has been stabilized, pressure and temperature are measured with two sensors and recorded to calculate the density of the test. The ignition system is discharged with a frequency of 0.2 hertz, this frequency is chosen because the coil requires a minimum load time and also because it ensures stable and long enough conditions in the electronic system to reproduce the same test. In order to perform a complete study and to evaluate the dispersion between tests, 10 discharges of the spark plug are recorded under the same ambient conditions. When the discharges occur all electrical signals are recorded. In every test, the following signals are recorded with high temporal resolution:

- Instantaneous primary intensity.

- Instantaneous primary voltage.

- Instantaneous secondary intensity.

- Instantaneous secondary voltage.

- Signal triggering the ignition system.

- Command pulse of the ignition system and high speed camera.

Other control parameters are recorded as average values, such as battery voltage, and pressure and temperature inside the chamber.

\section{Engine operation and measurement methodology}

The engine is operated under motor steady-state conditions. The experimental study is performed at low engine speed operation mode and it is controlled that the battery voltage system remains at $15 \mathrm{~V}$. Once all relevant parameters are stabilized for the test (engine temperature, intake gas temperature, intake and exhaust pressures, engine speed, oxygen concentration, etc.) and the acquisition systems are ready, the spark discharge is performed. It is critical, when studying the discharge between the electrodes, to control the conditions during the discharge process so that repeatability is ensured and a better understanding of the phenomena involved is achieved. The beginning of the discharge of the spark plug is determined by a signal simulated with the injection control; all systems are synchronized and allow phasing the spark with 
the engine pressure timing. The signal is used to initiate the spark plug charging and to start the high speed camera recording.

The configuration of the acquisition system was specifically modified to allow a convenient selection of the temporal windows for measurement. In such a way, the recording starts in the motored cycle immediately prior to a spark plug discharge cycle and concludes when the discharge cycle is completed. In every test, the following signals are recorded with high temporal resolution:

- Instantaneous in-cylinder pressure.

- Instantaneous intake/exhaust flow meter signals.

- Instantaneous air pressure at the intake/exhaust manifold.

- Instantaneous engine speed.

- Signal triggering the ignition system.

- Command pulse of the ignition system and high speed camera

Other control parameters are recorded as average values, such as water and oil temperatures, temperature at different points of the intake and exhaust systems, oxygen concentration, and all the electrical signals previously commented.

\section{In-chamber electrical signal analysis}

The electrical instrumentation (described above) used for measuring the main ignition system signals and the discharge of the spark plug is the same. The signals recorded are the conventional ones in automotive ignition systems: the primary and secondary intensities, and the primary and secondary voltages.

Once the different signals are stored and considering the transformation values of all electrical probes, it is necessary to correct the different signals with the aim of obtaining the real absolute value. Additionally, the integrated power delivered by the ignition system is obtained considering the secondary intensity and voltage, and performing the integral on the discharge time as shown by equation [1].

$$
E=\int_{t_{1}}^{t z} I \cdot V \cdot d t(1)
$$




\section{In-cylinder pressure analysis}

In-cylinder pressure analysis is made via the diagnostic model CALMEC [13]. This combustion diagnostic tool calculates the heat release law (HRL) when combustion occurs (which is not relevant in this study), and the temporal evolution of in-cylinder thermodynamic conditions, which is indeed relevant in the present study. This is calculated from the measured in-cylinder pressure by applying an energy balance to a control volume defined by the cylinder and the piston. Despite the fact that CALMEC was elaborated for systematic use in practically any Diesel engine configuration, it had to be adjusted for ignition system studies to ensure that even when the combustion does not occur, the appropriate density values due to heat transfer exist. CALMEC usually performs an analysis based on the cylinder pressure signal averaged over a certain number of cycles. But, in this case, the analysis must be done cycle by cycle because under the same thermodynamic conditions the response of the system can be different. 10 cycles are recorded at the same thermodynamic conditions.

\section{Optical techniques}

As commented previously, the same optical technique and the same high speed camera are used in both facilities. However, little differences exist in the methodology used in the ambient test rig and in the optical engine. The synchronization as well as the number of frames per second recorded are different for both systems. Furthermore, in the ambient temperature test rig the electrodes can be observed while in the optical single cylinder engine only the bottom of the spark is accessible. Natural luminosity radiation is acquired with a high speed camera for specific tests in order to complete and improve the information from electrical signals.

Finally, a temporal synchronization of images and current and voltage signals is performed. To sum up, with the methodology proposed it is possible to obtain:

- Information regarding the treatment of the recorded signals: charging time for the primary, maximum peak voltage for primary and secondary, maximum peak intensity for primary and secondary, profile of current discharge, time and integrated power released.

- Information regarding spatial visualization: location of the electric arc and light intensity. 
Once the signals and images have been recorded it is necessary to perform a post-processing step using a program implemented in Matlab code. With this program the electrical signals can be synchronized with all the images in both studies. Figure 6 and 7 are an example of the complete time-resolved parameters methodology along with some of their corresponding images.

Figures 6 and 7 depict the result of implementing the developed methodology that has been previously described. In the ambient test rig the case represented is $11.2 \mathrm{~kg} / \mathrm{m} 3$ density in chamber (Figure 6) and for the optical engine the case represented is that of the cycle with $14.7 \mathrm{~kg} / \mathrm{m} 3$ density in the combustion chamber (Figure 7). For both figures, from up to down in the vertical axis, secondary current and the integrated power and voltage measured in the secondary are represented. Besides, in the lower part of the graphic, the thermodynamic characteristics of the test are presented. In Figure 6, the three values are kept constant, where the pressure and temperature are measured and density is calculated. In Figure 7, only pressure is measured and CALMEC calculates the temperature and the density. Finally four sample pictures of the discharge process are shown at the bottom of the figures with emphasis in the evolution of the electric arc.

As can be seen in Figure 6, the peak values of secondary intensity and voltage are $118 \mathrm{~mA}$ and $23500 \mathrm{~V}$ approximately; that makes an integrated power of 113.4 mJ. In Figure 7 the peak values of these signals are $160 \mathrm{~mA}$ and $27000 \mathrm{~V}$, which implies an energy of approximately $154 \mathrm{~mJ}$. The ignition system charge (primary current evolution) is almost the same in both cases. The charge has an approximate duration of $4.6 \mathrm{~ms}$ and grows linearly until close to 12 amps in both cases. By contrast, comparing the system discharge represented by signals I2 and V2 (secondary current and voltage) it can be noticed that the discharge time is shorter in the cases of higher density, but the integrated energy is higher due to the increase in I2 and V2 needed to achieve the electrical breakdown. This is a consequence of the higher energy needed to establish the electric arc when the density is increased in the chamber, as could be the situation in new highly supercharged engines.

Published as: Experimental Techniques, Vol 38 (3), pages 17-28, May/June 2014 


\section{Results}

To evaluate the ignition system, density sweeps from ambient conditions up to values used in the new combustion gasoline modes are proposed. The different tests have been carried out in the two facilities previously presented. Table 1 presents the density values used on the ambient temperature test rig.

Table 2 presents the different density sweeps performed at the optical engine. The engine parameters selected are those which are expected to have a higher impact on the ignition process.

In the study of the optical engine a reference point is used. This point is SOS -19 CAD, an inlet temperature of $35^{\circ} \mathrm{C}$ and an oxygen concentration of $18 \%$ vol. Engine speed is kept constant during all the study at $750 \mathrm{rpm}$ and so is inlet pressure at $1.6 \mathrm{bar}$.

\section{Ambient temperature test rig}

An analysis of the ignition system is performed in the ambient temperature test rig by only varying the pressure to modify the value of the density. This allows to us study the effect of density on the ignition system at isolated conditions comparing with real engine conditions.

In Figure 8, the mean value and the standard deviation of the integrated power versus density is presented. For each test 10 repetitions have been performed. As can be seen in the figure, when density in chamber increases, the integrated power released during the arc phase of the spark event decreases. It can be contrasted by observing the trend of the integrated power mean value. This behavior is due to the fact that more density in chamber requires more energy to ionize the air and to obtain the arc breakdown, thus, the available energy for the arc phase decreases. This argument can be observed in the figure 9 . The figure shows the released power by the spark for two cases of density: $29.23 \mathrm{~kg} / \mathrm{m} 3$ and $1.1 \mathrm{~kg} / \mathrm{m} 3$, it can be appreciated that in the $29.23 \mathrm{~kg} / \mathrm{m} 3$ density case, the power value for the entire integration time is lower than in the $1.1 \mathrm{~kg} / \mathrm{m} 3$ case. Moreover the duration of the spark event is lower too, obtaining consequently a lower value of integrated power.

On the other hand, the dispersion of the integrated power values increases with density due to the difficulties encountered by the system when trying to establish the channel between electrodes at the high density values. 


\section{Optical engine results}

In order to compare the results obtained in the ambient test rig, different studies have been carried out in an optical engine by modifying those engine parameters that directly or indirectly affect the density. These parameters are the intake temperature and the start of spark (SOS). Thus, considering a closed volume, a variation in the intake temperature implies a variation in the chamber temperature as follows:

$$
T=T_{\text {intoks }} C R^{(n-1)}
$$

Where $\mathrm{n}$ is a polytrophic exponent which depends on the heat losses inside the combustion chamber. On the other hand, changes in the start of spark imply changes in both pressure and temperature. Finally, the effect of ambient composition is also tested. For that matter, different ratios of oxygen and nitrogen molar fractions are proposed.

Thus, starting with the density effects, a sweep of intake temperature is performed while the rest of the engine parameters that were selected as an engine reference point are kept constant. Once the temperature in the settling chamber is practically constant, 10 cycles of spark plug discharge are realized for each point. In Figure 10 is represented the main results of integrated power versus density. Each density corresponds to a specific intake temperature and therefore to a specific chamber temperature, while the pressure is kept constant. Consequently, this study complements the study performed with the ambient temperature test rig. The range of intake temperature is higher than the one used in a commercial engine in order to explore widely the effect that an increase in chamber temperature causes in the air between the electrodes and therefore in the ignition system. Thus, an increase in density, provided by the decrease in temperature, implies a decrease in the energy released between the electrodes. It is noted that the dispersion follows the same trend than in the ambient test rig.

In the second study a sweep of start of spark is carried out. When the start of spark is changed, the density is modified due to variations on pressure and temperature. As can be seen in Figure 11, variation on this engine parameter implies considerable variations on the density between the electrodes affecting the integrated power released by the ignition system. The integrated power trend obtained in this study, in which temperature and pressure have been modified, goes in the same way that in previous ones, where pressure has been kept constant and temperature has been modified and vice versa. On the other hand, the dispersion for these 10 discharges is similar for the three cases.

Published as: Experimental Techniques, Vol 38 (3), pages 17-28, May/June 2014 
Additionally, in order to get a better understanding of the operation of the ignition system, a sweep of oxygen concentration is performed. In these new combustion modes [10] high EGR levels are commonly used. With the system previously explained in the facilities section, the EGR is substituted with nitrogen and thus different XO2 concentrations can be obtained. The objective of this particular study is to observe how chamber gas composition affects the energy needed to ionize the gas between the electrodes.

Figure 12 presents three different XO2 concentrations (21 to $14 \%$ vol) (keeping the density constant) versus the integrated power. The results indicate that the effect of the oxygen concentration is negligible and no differences in integrated power can be appreciated, at least under these engine test conditions.

Finally, figure 13 presents a comparison between the results obtained in the ambient test rig and the optical engine in order to compare the trend and values of the integrated power versus density.

The results obtained with both facilities have similar trends and values, which allows concluding that using the ambient test rig is an adequate methodology to evaluate an engine ignition system in a simplified way.

\section{Conclusions}

A methodology for the characterization of spark ignition systems working at high density conditions has been presented, including the design of a simple test rig to visualize the ignition behavior under ambient temperature conditions. Also the description of the general schedule followed to process the different electrical signals and achieve the temporal synchronization of images has been provided.

The application of the described methodology provides an overall point of view of the ignition system behavior, complementing the classical approach which consists of the evaluation of this type of systems using only electrical signals. Specifically, the effect of variations of the density at ignition system has been evaluated by isolating the effects of pressure, temperature and gas composition, combining simplified and realistic test rigs. Thus, as a general conclusion, when the density is increased the integrated power required and supplied by the ignition system is decreased. Additionally, it is also remarkable that the values of the integrated power present higher dispersion with higher density values. Moreover, for a given compression ratio, the start of the spark is the most relevant parameter when defining the ignition system required for new gasoline combustion modes, since slight variations on this Published as: Experimental Techniques, Vol 38 (3), pages 17-28, May/June 2014 
parameter imply considerable variations on the density. On the other hand, the methodology developed also helps to identify problems regarding the location of the electric arc as well as its intensity and therefore its released energy at current high density conditions used in new gasoline engines.

Both the testing methodology and identification of errors in the ignition systems have been validated by examples with satisfactory results. Finally, it should be noted that the results of the ambient temperature test rig follow the same trends and values as the realistic ones. Therefore, it has been proved that the use of a simplified test rig could represent a useful optimization of time and resources in the research process.

\section{ACKNOWLEDGMENTS}

The authors wish to express their sincere thanks to Javier Monsalve and Daniel Lerida

\section{References}

[1] G. Banco, “An Analysis of the Federal Government’s Role in the Research and Development of Clean Diesels in the United States”, SAE 2004-01-1753, 2004.

[2] J.V. Benajes, R. Novella, A. García, and S. Arthozoul, "Partially Premixed Combustion in a Diesel Engine Induced by a Pilot Injection at the Low-pressure Top Dead Center”, Energy \& Fuels 2009, 23, 2891-2902.

[3] J.V. Benajes, J.J. López, R. Novella, and A. García, “Advanced Methodology for Improving Testing Efficiency in a Single cylinder Research Diesel Engine” Experimental Techniques Volume 32, Issue 6, November/December 2008, Pages: 41-47.

[4] F. Zhaoa, M.C. Laia, D.L. Harrington “Automotive spark-ignited direct-injection gasoline engines”, Progress in Energy and Combustion Science 25 (1999) 437-562

[5] A. Saitzokoff, R. Reinmann, T. Berglind, and M. Glavmo, "An Ionization Equilibrium Analysis of the Spark Plug an Ionization Sensor”, SAE paper 960337, 1996.

[6] S.S. Chung and JYul Ha, W.Young Park, M. Jun Lee, "A Study on a Spark Plug for Charging of Stratified Mixture in a Local Area”, SAE paper 2003-01-3213.

[7] N. Kondo, T. Suzuki, Y. Sakakura and T. Yamada, “Combustion Monitoring by use of the Spark Plug for DI Engine” SAE paper 2001-01-0994

Published as: Experimental Techniques, Vol 38 (3), pages 17-28, May/June 2014 
[8] Y. Shimanokami, Y. Matsubara, T. Suzuki and W. Matsutani, “Development of High Ignitability with Small Size Spark Plug”, SAE paper 2004-01-0987.

[9] M. Jun Lee, M. Hall, Ofodike A. Ezekoye and R. Matthews "Voltage, and Energy Depositation Characteristics of Spark Ignition Systems”. Department of Mechanical Engineering. University of Texas at Austin. SAE paper 2005-01-0231

[10] R. van Basshuyensen, “Gasoline Engine with Direct Injection: Processes, Systems, Development and Potential”, GWM Fachverlage GmbH, chapter 3,Wiesbaden 2009,

[11] J.M. Desantes; R. Payri; F.J. Salvador; V. Soare, “Determination of diesel sprays characteristics in real engine in-cylinder air density and pressure conditions”. J Mech. Sci. Technol. 19, 2040-2052. 2005 [12] R. Payri, F.J. Salvador, J. Gimeno, J. de la Morena, "Study of cavitation phenomena based on a technique for visualizing bubbles in a liquid pressurized chamber", International Journal of Heat and Fluid Flow, Vol 30 (4), pp. 768-779, 2009

[13] Lapuerta M, Armas O. and Hernandez J. "Diagnostic of diesel combustion from in-cylinder pressure signal by estimation of mean thermodynamic properties of gas. Appl. Therm. Eng. 19 513-29. 1999 


\section{LIST OF FIGURE CAPTIONS}

Figure 1: Scheme of the ambient temperature facility.

Figure 2: Different views of the parts which form the nitrogen test rig.

Figure 3: Complete test cell scheme for the optical engine.

Figure 4: Sketch of the optical access in the cylinder engine and an image showing how the combustion chamber is seen from the camera point of view.

Figure 5: Sketch of the methodology applied to perform the ignition system study.

Figure 6: Representation of the main electrical and thermodynamic signals of $11.2 \mathrm{~kg} / \mathrm{m}^{3}$ on the ambient test rig.

Figure 7: Representation of the main electrical and thermodynamic signals of $14.7 \mathrm{~kg} / \mathrm{m}^{3}$ on the optical engine.

Figure 8: Integrated power with different densities on the test rig.

Figure 9: Logarithmic instantaneous power with 2 different densities.

Figure10: Integrated power with different densities on the optical engine. Temperature sweep.

Figure 11: Integrated power with different densities on the optical engine. Start of spark timing sweep.

Figure 12: Integrated power with different densities on the optical engine. Oxygen concentration sweep.

Figure 13: Ambient temperature test Rig and optical engine integrated power results. 


\section{TABLES}

\begin{tabular}{cccc}
\hline Test & Pressure & Density & Characteristics \\
\hline$[-]$ & {$[$ bar] } & {$\left[\mathrm{kg} / \mathrm{m}^{3}\right]$} & {$[-]$} \\
1 & Atm & 1.11 & Spark plug ignition \\
2 & 10 & 11.1 & Frequency: $\mathbf{0 . 2 0 ~ H z}$ \\
3 & 15 & 16.7 & 10 Ignition cycles \\
4 & 20 & $\mathbf{2 2 . 2}$ & recorded per density \\
5 & $\mathbf{2 5}$ & $\mathbf{2 7 . 8}$ & T=298K Constant \\
\hline
\end{tabular}

Table 1: Test Matrix to validate the methodology with different densities in the high pressure test rig

\begin{tabular}{lll}
\hline Parameter & Unit & Sweep \\
\hline Start of Spark Ignition & {$[$ CAD $]$} & $-\mathbf{1 9} /-14 /-9$ \\
Intake Temperature & {$\left[{ }^{\circ} \mathrm{C}\right]$} & $\mathbf{3 5} / \mathbf{5 0} / \mathbf{7 0} / \mathbf{9 0} / \mathbf{1 1 0}$ \\
Intake oxygen concentration & {$[\%$ vol] } & $\mathbf{2 1 / 1 6 / 1 4}$ \\
\hline
\end{tabular}

Table 2: Test Matrix to validate the methodology with different densities in the optical engine 
Figure 1: Scheme of the ambient temperature facility.

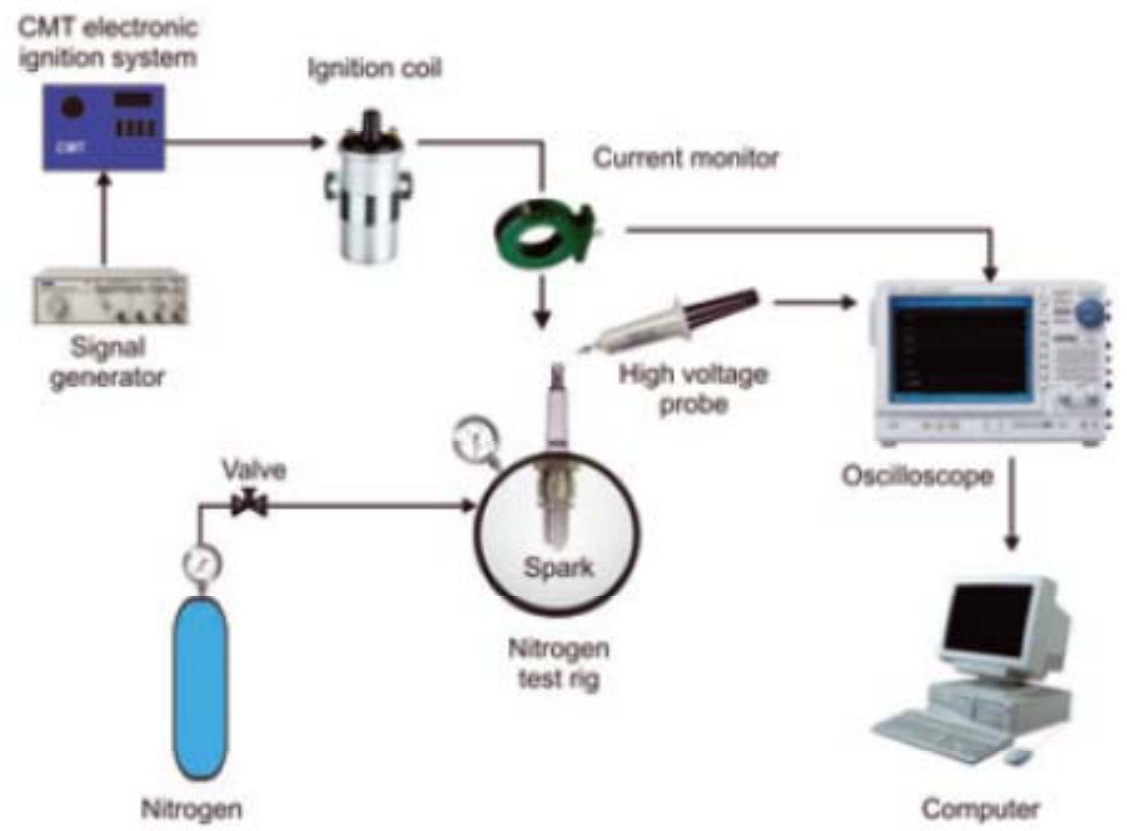

Figure 2: Different views of the parts which form the nitrogen test rig.

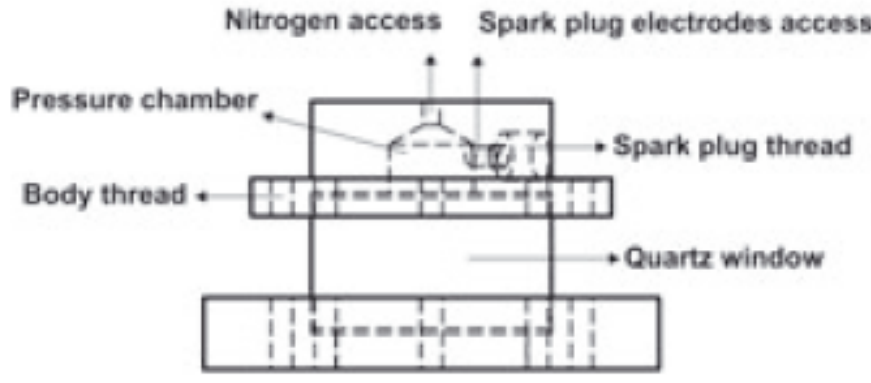

1. Elevation
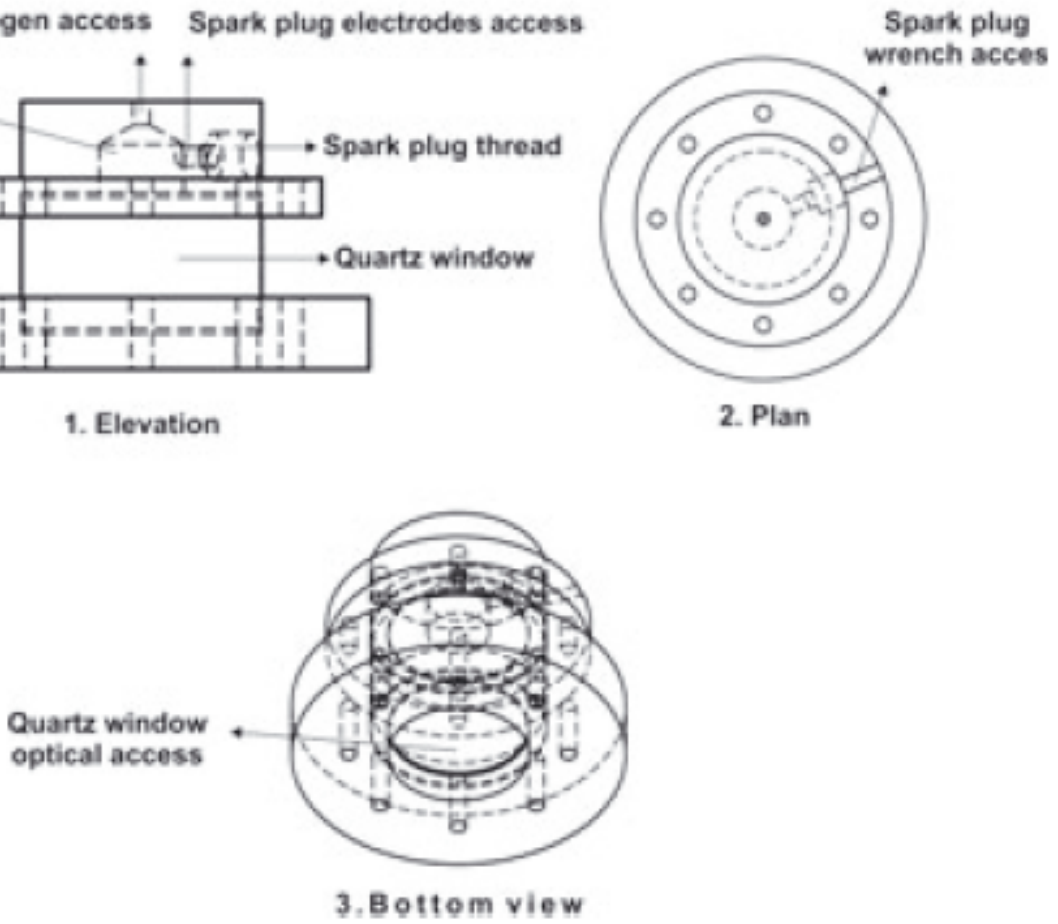

Published as: Experimental Techniques, Vol 38 (3), pages 17-28, May/June 2014 
Figure 3: Complete test cell scheme for the optical engine.

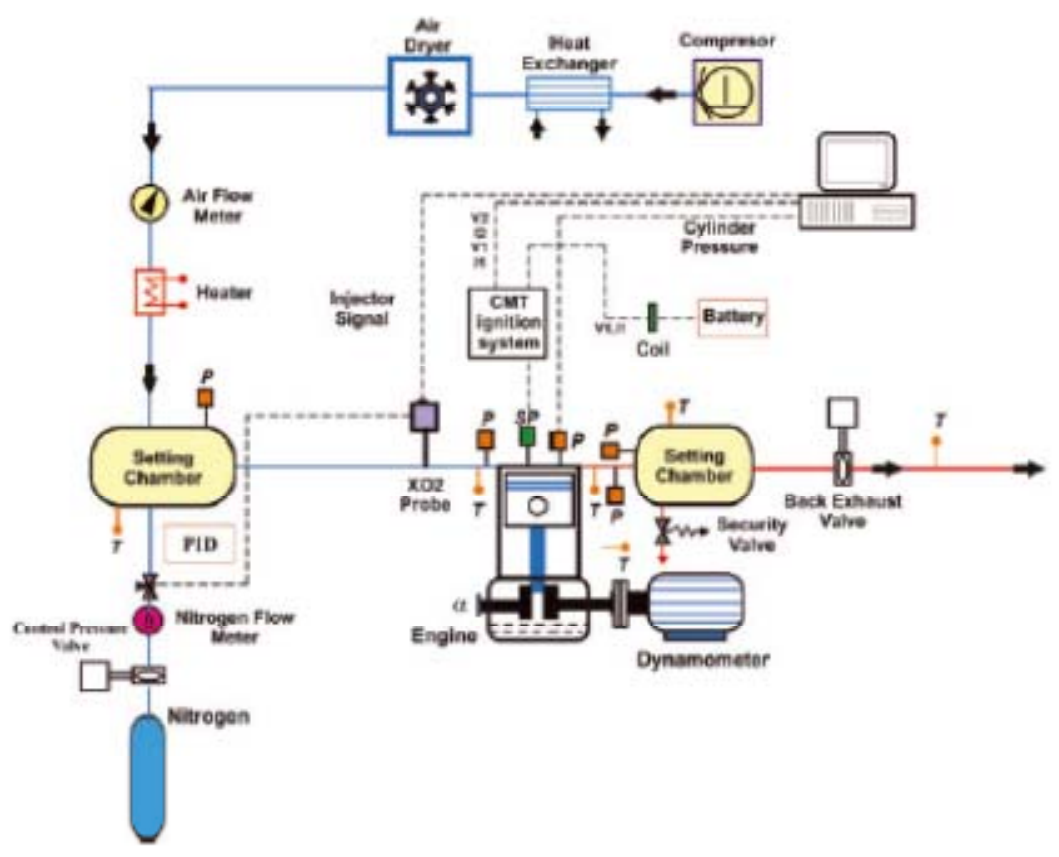

Figure 4: Sketch of the optical access in the cylinder engine and an image showing how the combustion chamber is seen from the camera point of view.

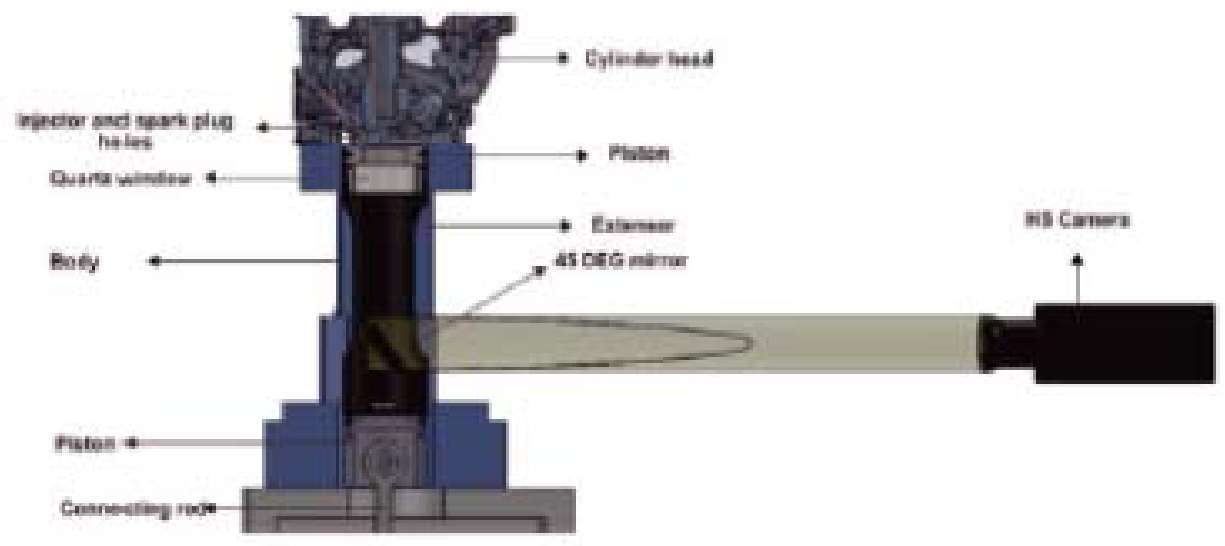


Figure 5: Sketch of the methodology applied to perform the ignition system study.

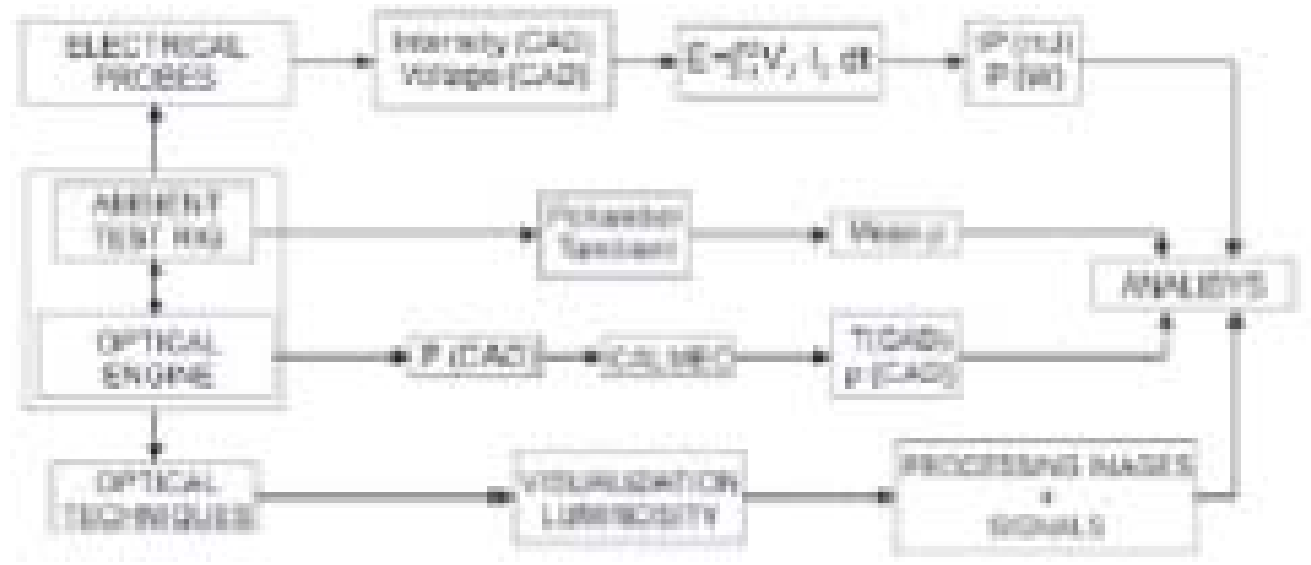

Figure 6: Representation of the main electrical and thermodynamic signals of $11.2 \mathrm{~kg} / \mathrm{m}^{3}$ on the ambient test rig.
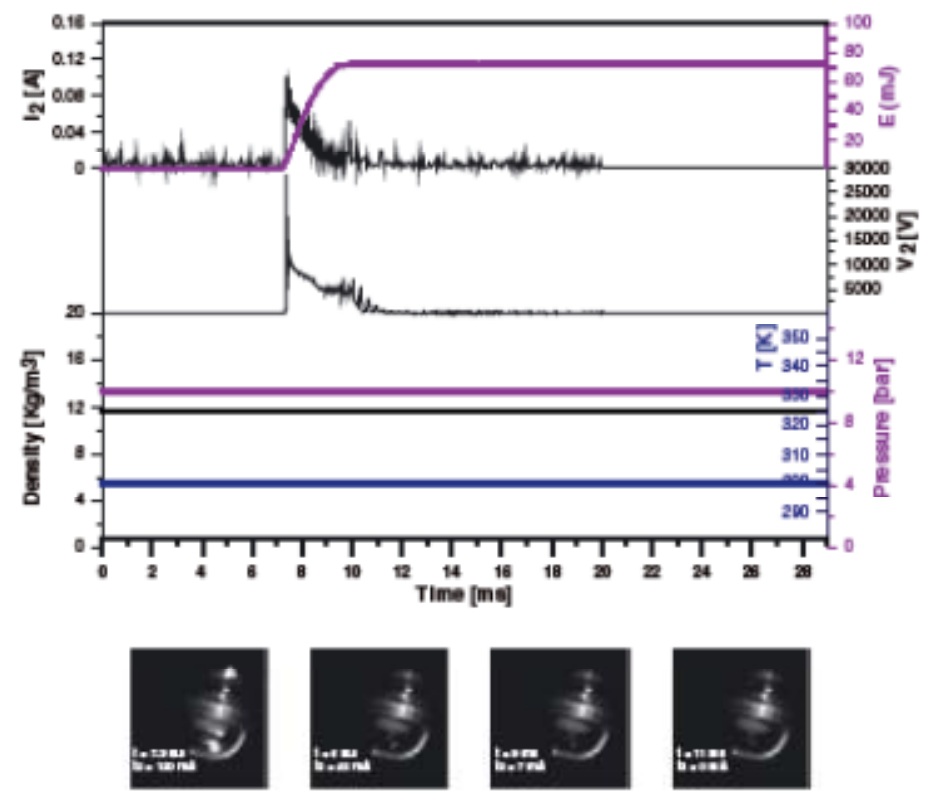

Published as: Experimental Techniques, Vol 38 (3), pages 17-28, May/June 2014 
Figure 7: Representation of the main electrical and thermodynamic signals of $14.7 \mathrm{~kg} / \mathrm{m}^{3}$ on the optical engine.

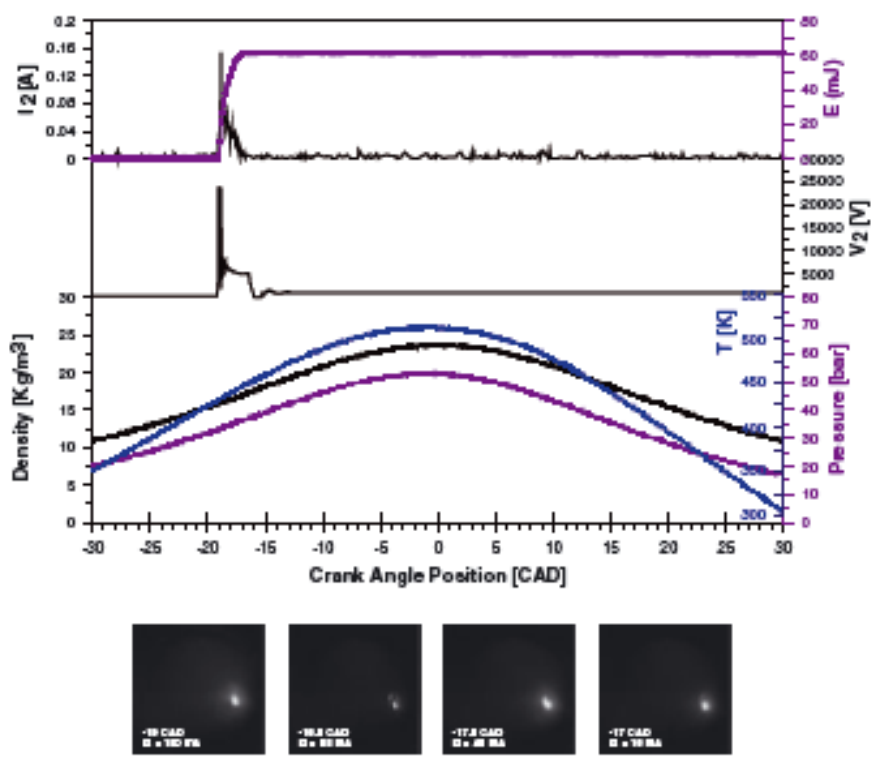

Figure 8: Integrated power with different densities on the test rig.

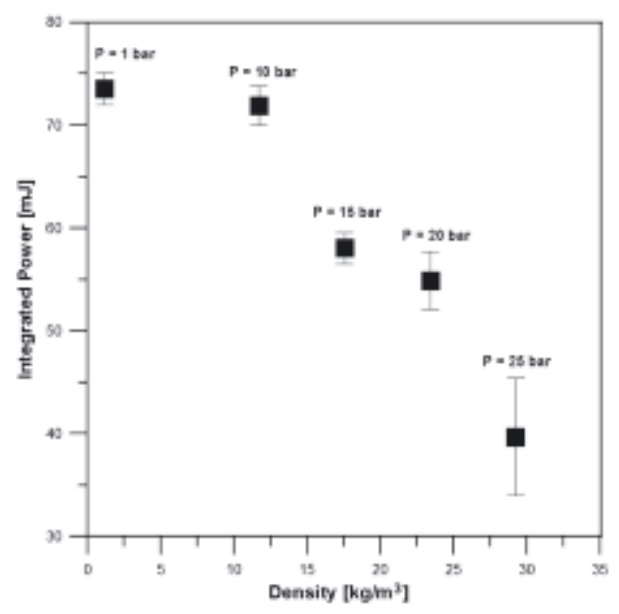


Figure 9: Logarithmic instantaneous power with 2 different densities.

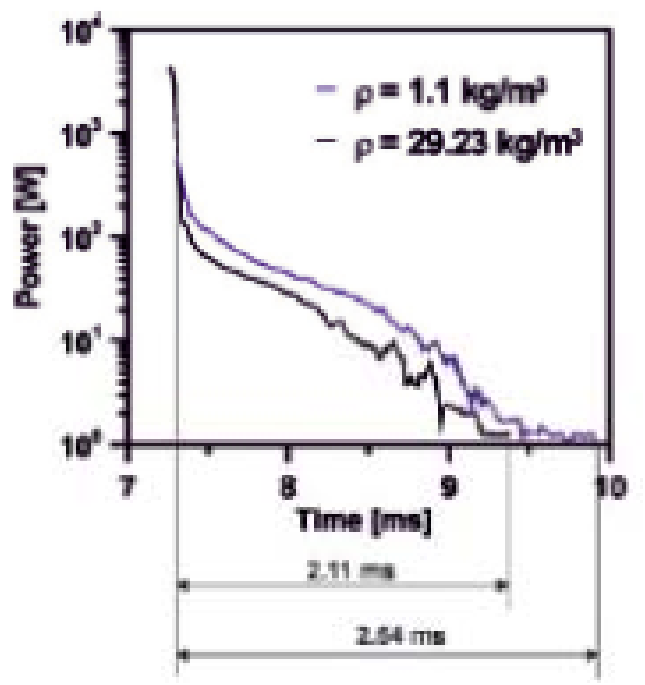

Figure10: Integrated power with different densities on the optical engine. Temperature sweep.

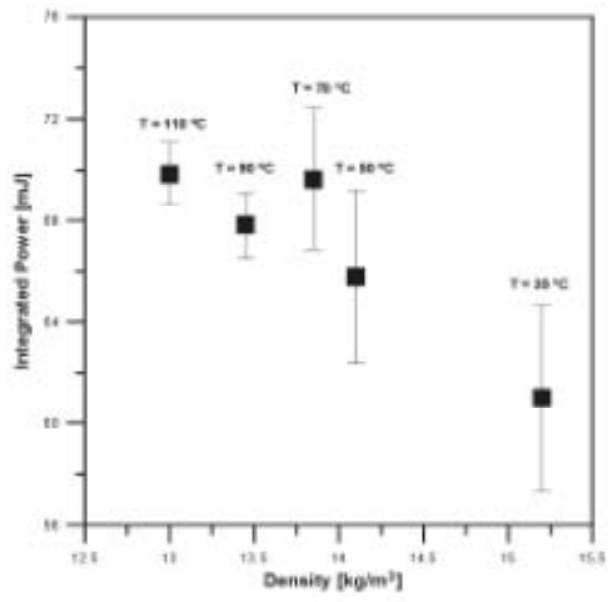

Published as: Experimental Techniques, Vol 38 (3), pages 17-28, May/June 2014 
Figure 11: Integrated power with different densities on the optical engine. Start of spark timing sweep.

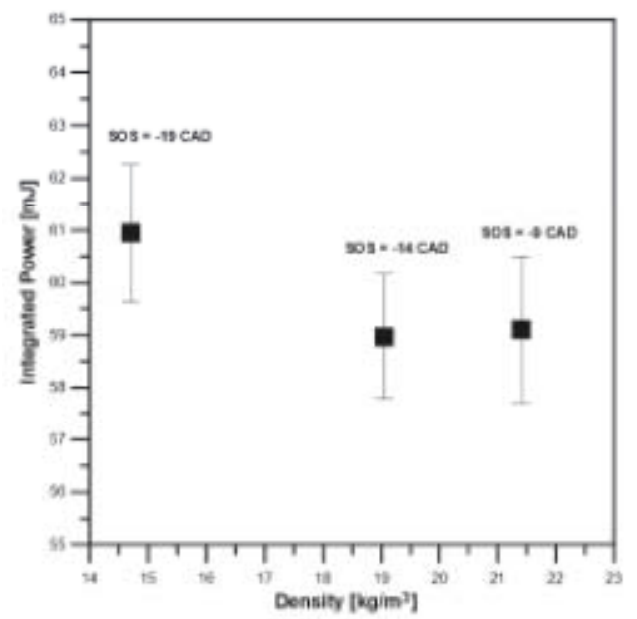

Figure 12: Integrated power with different densities on the optical engine. Oxygen concentration sweep.

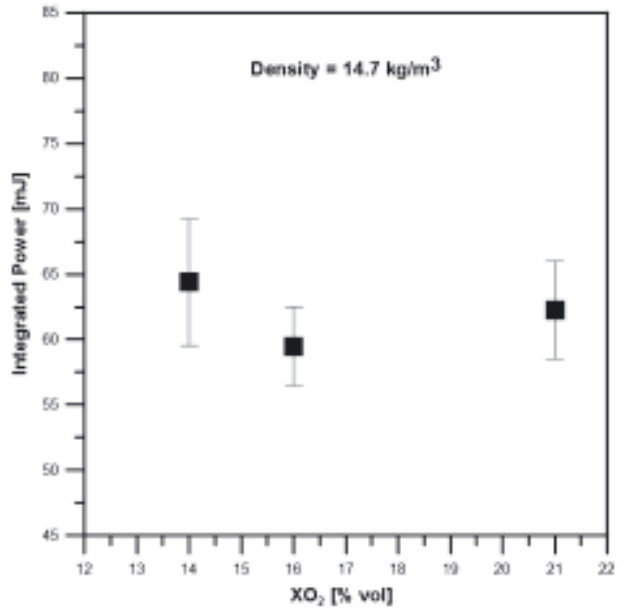

Published as: Experimental Techniques, Vol 38 (3), pages 17-28, May/June 2014 
Figure 13: Ambient temperature test Rig and optical engine integrated power results.

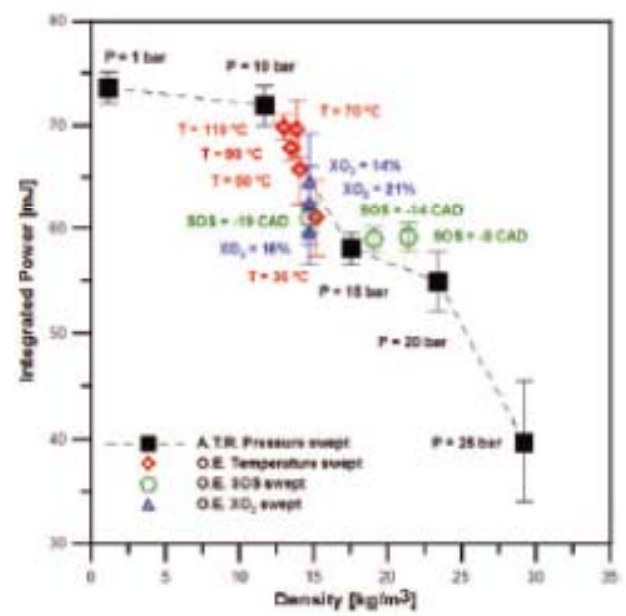

Published as: Experimental Techniques, Vol 38 (3), pages 17-28, May/June 2014 